\title{
Editorial: Plant Seed Oils and Their Potential for Biofuel Production
}

\author{
Kaniki Tumba ${ }^{1}$, Timothy P. Durrett ${ }^{2}$, Subramaniapillai $\mathrm{Niju}^{3}$, Tunde Victor Ojumu ${ }^{4}$, \\ Martin Safari Tango ${ }^{5}$ and Eriola Betiku ${ }^{6 *}$ \\ ${ }^{1}$ Department of Chemical Engineering, Mangosuthu University of Technology, Umlazi, South Africa, ${ }^{2}$ Department of Biochemistry \\ and Molecular Biophysics, Kansas State University, Manhattan, KS, United States, ${ }^{3}$ Department of Biotechnology, PSG College \\ of Technology, Coimbatore, India, ${ }^{4}$ Department of Chemical Engineering, Cape Peninsula University of Technology, Cape Town, \\ South Africa, ${ }^{5}$ School of Engineering, Acadia University, Wolfville, NS, Canada, ${ }^{6}$ Department of Chemical Engineering, Obafemi \\ Awolowo University, Ile-Ife, Nigeria
}

Keywords: vegetable oil, biodiesel, transesterfication, catalyst, modeling, optimization, artificial inteligence-Al, response surface (RS) methodology

\section{Editorial on the Research Topic}

\section{Plant Seed Oils and Their Potential for Biofuel Production}

Oils derived from plant seeds and microalgae comprise mainly triacylglycerols (TAG) molecules with very high energy density, making them an ideal source for biofuels. These renewable energy sources for transportation are increasingly in demand by societies because they do not raise global carbon dioxide levels. The most common biofuel derived from seed oils is biodiesel, which consists of the fatty acid methyl esters (FAME) produced from the TAG molecules. More recently, renewable aviation fuels termed "biojet" have been synthesized from seed oils through hydroprocessing. The economics of production limits the widespread adoption of fuels derived from seed and microalgal oils. For example, the available oil feedstock is not enough for the fuel market size (Durrett et al., 2008), and it often represents the highest cost of production (Veljković et al., 2018). While increasing seed oil production would help offset these problems, it should be done in a sustainable manner that does not destroy existing ecosystems or compete with food production. Also, biodiesel derived from some vegetable oils suffers poor cold-temperature properties and is prone to oxidation compared to conventional diesel. Solving these problems requires multidisciplinary approaches, some of which are presented in this Research Topic.

The first part of this Research Topic contains three articles that broadly consider different problems relating to the physical properties and profitability of biodiesel and solutions to them. The factors contributing to the cold flow problems of biodiesel and the crystallization mechanism, which often lead to blockage of both the fuel filters and the fuel line, were discussed (Hazrat et al.). The authors compared the effectiveness of winterization and the use of additives to improve the cold temperature properties of biodiesel.

Microalgae are another promising renewable source of oil that can be used for biofuel production. However, microalgal biodiesel production is not currently economically viable. In their extensive review article, Mutanda et al. describe a biorefinery approach to derive other microalgal products, such as pigments and high-value lipids. The authors consider ways to improve microalgal production, including selecting appropriate strain, cell growth, extraction of compounds, and genetic manipulations.

Pennycress (Thlaspi arvense) is being developed as an oilseed cash cover crop grown over the winter in the United States Midwest corn belt and thus does not compete with the production of food crops (Sedbrook et al., 2014). Esfahanian et al. implemented a synthetic biology approach to improve the quality of the oil produced by this crop for biojet and biofuel applications. In their study, the 
authors express enzymes from other plant species that produce medium-chain fatty acids or low-viscosity acetyl-TAGs in developing pennycress seeds. Depending on the combination of enzymes used, different types of medium-chain fatty acids or acetyl-TAGs were successfully produced, thus enabling the use of pennycress for various biofuel applications.

The second part of this Research Topic consists of four articles. They present investigations on non-edible oils extracted from castor, tobacco, neem, or Croton gratissimus seeds as feedstock for biodiesel production. The effectiveness of some catalysts is validated for the investigated biodiesel feedstock. Emphasis is put on the effect of various process variables on biodiesel yields. Various modeling approaches are proposed to determine optimal operating conditions, considering factors such as temperature, catalyst nature, catalyst concentration, methanol-to-oil ratio, and agitation speed.

Tumba et al. report the preparation of monoclinic-phased sulfated zirconia $\left(\mathrm{SO}_{4}{ }^{2-} / \mathrm{ZrO}_{2}\right)$ acid catalyst that showed high activity in the esterification of high free fatty acid leading to high FAME yield and purity of the biodiesel produced in the subsequent transesterification of the esterified oil using $\mathrm{KOH}$ as a base catalyst. Karmakar et al. showed that a one-step transesterification could be achieved using sulfonated biomass waste (Mesua ferrea Linn seed shell). In both studies, the authors used response surface methodology (RSM) combined with central composite design (CCD) as a DOE strategy. An opportunity offered by agricultural wastes for cost-effective and environmentally friendly feedstock for biodiesel production was demonstrated (Karmakar et al.).

The application of artificial intelligence (AI) was demonstrated by Okpalaeke et al. and Samuel et al. in the

\section{REFERENCES}

Durrett, T. P., Benning, C., and Ohlrogge, J. (2008). Plant Triacylglycerols as Feedstocks for the Production of Biofuels. Plant J. 54, 593-607. doi:10.1111/ j.1365-313x.2008.03442.x

Sedbrook, J. C., Phippen, W. B., and Marks, M. D. (2014). New Approaches to Facilitate Rapid Domestication of a Wild Plant to an Oilseed Crop: Example Pennycress (Thlaspi Arvense L). Plant Sci. 227, 122-132. doi:10.1016/ j.plantsci.2014.07.008

Veljković, V. B., Biberdžić, M. O., Banković-Ilić, I. B., Djalović, I. G., Tasić, M. B., Nježić, Z. B., et al. (2018). Biodiesel Production from Corn Oil: a Review. Renew. Sustain. Energ. Rev. 91, 531-548. doi:10.1016/ j.rser.2018.04.024 modeling and optimization of biodiesel production from seed oils. Okpalaeke et al. reported that while artificial neural network (ANN) and RSM exhibit good performance in terms of the discrepancy between experimental and calculated data in the esterification of neem oil, genetic algorithm (GA) was demonstrated as a better optimization tool than RSM in the study. It was shown that ferric sulfate is an effective acid catalyst for neem seed oil esterification. Samuel et al. use data obtained in the literature to model biodiesel production from tobacco seed oil. After successfully correlating reaction time, temperature, methanol-to-oil molar ratio, and catalyst amount $(\mathrm{KOH})$ with biodiesel yield, it emerges that the adaptive neuro-fuzzy inference system (ANFIS) is superior to ANN as a modeling tool for the transesterification of tobacco seed oil.

In summary, the articles in this special Research Topic described approaches that address various factors limiting the widespread adoption of biofuels derived from seed oils. The work provides solutions for some problems encountered at different stages in biodiesel production and utilization, though further work is needed to ensure that biodiesel can significantly contribute to the world's energy needs.

\section{AUTHOR CONTRIBUTIONS}

KT and TD wrote the article with input from SN, TO, MT, and EB. All authors approved it for publication.

Conflict of Interest: The authors declare that the research was conducted in the absence of any commercial or financial relationships that could be construed as a potential conflict of interest.

Publisher's Note: All claims expressed in this article are solely those of the authors and do not necessarily represent those of their affiliated organizations, or those of the publisher, the editors and the reviewers. Any product that may be evaluated in this article, or claim that may be made by its manufacturer, is not guaranteed or endorsed by the publisher.

Copyright @ 2021 Tumba, Durrett, Niju, Ojumu, Tango and Betiku. This is an openaccess article distributed under the terms of the Creative Commons Attribution License (CC BY). The use, distribution or reproduction in other forums is permitted, provided the original author(s) and the copyright owner(s) are credited and that the original publication in this journal is cited, in accordance with accepted academic practice. No use, distribution or reproduction is permitted which does not comply with these terms. 